\title{
Correlation between attitudes, concerns, self-efficacy and teaching intentions in inclusive education evidence from German pre-service teachers using international scales
}

\author{
Susanne Miesera ${ }^{1}$ (D), Jeffrey M. DeVries ${ }^{2}$ (D) Jana Jungjohann ${ }^{2}$ and Markus Gebhardt ${ }^{2}$ \\ ${ }^{1}$ Technische Universität München, Germany; ${ }^{2}$ Technische Universität Dortmund, Germany
}

Key words: Inclusion, teacher education, Germany, attitudes, concerns, self-efficacy.

\begin{abstract}
The inclusion of pupils with special educational needs (SEN) in schools is an ongoing challenge - it demands the development of an adapted teaching and learning environment, which, in turn, requires a corresponding teacher education programme. Studies indicate that personal characteristics of the respective teachers are one of the main influencing factors on the classroom environment. This article reports on a study of the role of teacherrelated factors, attitudes, concerns and efficacy in inclusion by testing existing survey instruments of 909 pre-service teachers in Germany. A confirmatory factor analysis was applied to new German translations of four instruments: Attitudes Towards Inclusion Scale, Intention to Teach in Inclusive Classroom Scale, Concerns about Inclusive Education Scale, and the Teacher Efficacy for Inclusive Practices. With minor modifications, models demonstrated good fit measures and partial measurement invariance between special school preservice teachers and general pre-service teachers. A combined model of all four scales confirmed that lower concerns were related to attitudes that are more positive, greater self-efficacy and stronger intentions to teaching inclusively. Implications for teacher-training and comparisons to other international samples are discussed.
\end{abstract}

\section{Introduction}

With the ratification of the UN Convention 2009 (United Nations, 2006), Germany became obligated to implement the law in schools and teacher-training. Consequently, students with and without special educational needs (SEN) were placed together in inclusive schools. The increasing heterogeneity in schools presents teachers with new challenges. In order to meet the needs of all the students, adaptations to the qualifications of educational staff are required. Apart from the knowledge and skills in teaching inclusive classes, teachers' attitudes, self-efficacy, and concerns (i.e. worries that might inhibit realization) strongly affect the implementation of inclusion in the classroom (Avramidis and Norwich, 2002; Boyle, Topping and Jindal-Snape, 2013; Shaukat, Sharma and Furlonger, 2013; Specht, 2016). With regards to these personal factors, different studies highlight the role of the respective teachers' training and education (Florian, Young and Rouse, 2010; Forlin, 2010; Loreman, Earle, Sharma, et al., 2007; Sharma and Sokal, 2015). The development of the individual personal characteristics, specifically attitudes and perceived self-efficacy, in pre-services teachers depends in part on their qualifications obtained in their teacher education training (Beacham and Rouse, 2012; Hernandez, Hueck and Charley, 2016; Kim, 2011; Romi and Leyser, 2006). This study expands upon the international adaptions of four instruments by adapting them to a German language and sample. Furthermore, we provide a deeper model of the relationship of the personal factors to each other by developing a combined model, which allows for the direct comparison of the covariation between scores on each instrument. This is an improvement upon the work of past studies where mainly only sum or average scores of instruments results were compared (Forlin, Sharma and Loreman, 2014; Loreman, Sharma and Forlin, 2013; Sokal, Woloshyn and Funk-Unrau, 2013). Lastly, we compare survey results of pre-service teachers training for special education with those to be general teachers, and we provide one of the first assessments of measurement invariance of these instruments across these groups, which is required for any comparison of instrument scores to be valid.

Teachers' personal characteristics

Besides legislative, financial resources and teachertraining, teacher-related factors are important for the successful implementation of inclusion (Forlin, Loreman, Sharma, et al., 2009; Loreman, Forlin and Sharma, 2014). 
Loreman, Forlin, and Sharma (2014) examined indicators for inclusive education in a literature review. These include attitudes, concerns, and perceived self-efficacy, which are discussed in the following four sections. For a clearer understanding of the literature in these areas, we discuss them separately. However, many studies do investigate more than one of these concepts.

\section{Attitudes to inclusion}

Perhaps the most comprehensive review of attitudes to inclusion was conducted by Avramidis and Norwich (2002) in the 1980s through to the early 2000s; it highlighted the importance of teacher-related factors affecting attitudes towards inclusion. A number of teacher variables, such as gender, age, teaching experience, and contact with individuals with SEN, have been linked to attitudes towards inclusive education. A meta-study in 2011 examined the influencing factors in respect of teachers' attitudes to inclusive education (de Boer, Pijl and Minnaert, 2011); they outline, in addition to variables such as gender or type of disability, experience of inclusive education and teacher-training as the main aspects. Although most of the studies show different results in respect of the variables, experience of inclusive education is shown to have a positive impact in all the review studies (de Boer, Pijl, and Minnaert, 2011). Social contact with special-needs students appears to lead to more positive teacher attitudes (Ahmmed, Sharma and Deppeler, 2012; Boyle, Topping, and Jindal-Snape, 2013; Brownlee and Carrington, 2000; Sharma, Forlin, Loreman, et al., 2006), as does private contact with friends or families with disabilities (Specht, 2016). Several studies have supported these effects across diverse nations and cultures (Miesera and Gebhardt, 2018; Saloviita and Schaffus, 2016; Shaukat, Sharma, and Furlonger, 2013).

Since Avramidis and Norwich's (2002) review, which broadly demonstrated teacher-training courses resulting in more positive teacher attitudes towards inclusion, much research has been conducted which examines the features of effective courses. Sokal and Katz (2017) showed the diverse outcomes of training, such as better attitudes, reduced concerns, improved self-efficacy, and greater knowledge. Copfer and Specht (2014) summarized '... it is necessary to provide consistent and ongoing professional development opportunities for preservice and inservice teachers to increase their attitudes...' (p. 107). In their transnational study over four different countries, Forlin, Loreman, Sharma, et al. (2009) found that '... pre-service teacher attitudes towards inclusion and their sentiments about people with disabilities became significantly more positive, and their concerns decreased, following involvement in a unit of work focusing specifically on inclusive education...' (p. 206). The majority of studies underline that no single variable '. . alone could be regarded as a strong predictor of educator attitudes' (Avramidis and Norwich, 2002, p. 142).

\section{Concerns about inclusion}

Teacher concerns regarding inclusion could aggravate or inhibit its school implementation. As with attitudes, different factors influence concerns. Sharma, Forlin, Loreman, et al. (2006) conducted a study to measure the differences in concerns among pre-service teachers in four places. Notably, participants across all locations rated a lack of resources as a major concern, followed by the lack of skills (Sharma, Forlin and Loreman, 2007). The study showed a significant relationship between a high level of confidence in teaching students with disabilities, a good knowledge of inclusion, and contact with a person with a disability, and fewer concerns (Sharma, Forlin, and Loreman, 2007). In a study in India, Sharma, Moore and Sonawane (2009) confirmed this, finding the greatest concerns to be a lack of resources. Lack of resources is not the only significant concern. In fact, the concern construct is multi-dimensional and relates to other factors such as acceptance of students with special need or teacher workload (Sharma and Desai, 2002). In the next section, we discuss these aspects further. In 2008, a pre- and post-test study measured the effects of teacher education courses covering inclusion on teachers' attitudes and concerns about inclusive education (Sharma, Forlin and Loreman, 2008). In Canada, Australia and Singapore overall concerns decreased significantly, compared with Hong Kong, where concerns decreased only in some aspects. The researchers conclude: 'It is important, though, that preservice teachers' concerns about implementing inclusion are addressed as much as possible during their teacher preparation programmes' (Sharma, Forlin, and Loreman, 2008, p. 783). Golmic and Hansen (2012) pointed out that attendance of inclusive education courses for pre-service teachers could improve attitudes and reduce overall concerns.

\section{Perceived self-efficacy in inclusive teaching}

Successful implementation of inclusion in classrooms greatly depends on teachers' self-efficacy, as defined by Bandura (1997). Romi and Leyser (2006) specified that positive perceived self-efficacy is associated with a supportive teacher behaviour in inclusive classes. This includes, being '..less critical of student errors, and work [ing] longer with a student who is struggling' (Romi and Leyser, 2006, p. 88). Sharma, Loreman and Forlin (2012) developed the Teacher Efficacy for Inclusive Practices (TEIP) scale to measure the factors of self-efficacy. A study in India, with over 1600 pre-service teachers, found by using the TEIP scale that the quality of teacher education programmes is determined by appropriate content, rather than the length of the programmes fostering selfefficacy (Ahsan, Deppeler and Sharma, 2013). The study showed a significant positive correlation between preservice teachers' perceived self-efficacy and their attitudes towards inclusive education (Ahsan, Sharma and Deppeler, 2012). In the same study, multiple regression analysis indicated positive predictors for strong self-efficacy are: knowledge of the local legislation; confidence in 
teaching students with a disability; and significant interaction in dealings with a person with disability (Ahsan, Sharma, and Deppeler, 2012). Savolainen, Engelbrecht, Nel, et al. (2012) conducted a cross-country analysis of teachers' attitudes and self-efficacy in inclusive education of preservice and in-service teachers in Finland and South Africa. They found out that the overall self-efficacy on inclusive practice was relatively high in both countries (Savolainen, Engelbrecht, Nel, et al., 2012). For instance, Sharma and Sokal $(2015,2016)$ identified better self-efficacy of pre-service teachers after they had attended an inclusive education course.

Lastly, researchers have repeatedly concluded that if teachers have the appropriate knowledge, skills, and confidence, they will have a more positive attitude to inclusion (Sharma, Forlin, and Loreman, 2008; Subban and Mahlo, 2017; Swain, Nordness and Leader-Janssen, 2012). In turn, teachers' attitudes will affect the implementation and effectiveness of inclusive classrooms (Ahsan, Sharma, and Deppeler, 2012; Florian and BlackHawkins, 2011; Jordan, Glenn and McGhie-Richmond, 2010; Specht, McGhie-Richmond, Loreman, et al., 2016). Teacher education is, therefore, crucial in developing teachers' more positive attitudes and perceived self-efficacy, and in reducing concerns.

\section{Development of the scales to measure teacher personal factors on inclusion}

Attempts to explain these results have made the measurement of teacher personal factors and their predictors more important in the last 15 years. Various instruments have been developed to measure attitudes, concerns, self-efficacy and inclusive practices in diverse samples and countries (Antonak and Larrivee, 1995; Kopp, 2009; Stoiber, Gettinger and Goetz, 1998). Forlin, Loreman and Sharma in particular developed scales and examined their structure in different countries (Forlin and Chambers, 2011; Loreman, Earle, Sharma, et al., 2007; Sharma, Loreman, and Forlin, 2012). Our first research goal is to expand these to a new group: German pre-service teachers. Below, we discuss the findings in other countries, which will help guide our predictions in our German sample. Specifically, we discuss four instruments: Attitudes towards Inclusion Scale (AIS) and Intention to Teach in an Inclusive Classroom Scale (ITICS) (Sharma and Jacobs, 2016), Concerns about Inclusive Education Scale (CIES) (Sharma and Desai, 2002), as well as TEIP (Sharma, Loreman, and Forlin, 2012). These four scales were validated and reliable in a variety of national and international studies in different languages. The scales have established factor-analysis (Ahsan, Sharma, and Deppeler, 2012; O'Toole and Burke, 2013; Savolainen, Engelbrecht, Nel, et al., 2012; Sharma and Nuttal, 2016).

\section{Attitudes scales}

Many instruments have been developed to measure attitudes towards inclusion (Kopp, 2009; Schwab, Gebhardt,
Ederer-Fick, et al., 2012; Stoiber, Gettinger, and Goetz, 1998). Some surveys are more concerned with specialneeds education, and some focus more on general education practice. We have decided, however, to use the various instruments of the Forlin, Loreman and Sharma group, because they have developed their scales in successive cycles over the last decade and have examined the structure and the results of the instruments in different countries. This has built a broad research base for us to compare our results with theirs.

The AIS was designed to measure teachers' attitudes towards inclusion. It consists of ten seven-point Likert items, ranging from strongly disagree (1) to strongly agree (7). Sharma and Jacobs (2016) calculated the scale with data from Indian (314) and Australian (245) in-service teachers. The structural equation model (SEM)-based factor analysis resulted in two independent scales. The first included items one to four, which measure the beliefs about inclusion, and the second included items seven to ten, which measure feelings about inclusion (Sharma and Jacobs, 2016). The attitudes scale exhibits sufficient levels of reliability ( $\geq 0.74)$. The ITICS was first used in the same study (Sharma and Jacobs, 2016). In contrast with the AIS, the target of the items was on actions, rather than beliefs. A seven-point Likert Scale, ranging from extremely unlikely to extremely likely, rated the responses. Like the AIS, the ITICS led to a two-factor model. The ITICS defines 'intention to implement curriculum changes' and 'intention to consult with others' as constructs. As with the AIS, the first construct, 'intention to consult', showed acceptable levels of reliability $(\geq 0.74)$, but the reliability of the 'intention to change curriculum' subscale was below 0.7 (Sharma and Jacobs, 2016). The authors suggested to remove two negatively formulated items and they proposed to add items in future research (Sharma and Jacobs, 2016).

\section{Concern scale}

Sharma and Desai (2002) developed a scale to measure concerns. They emphasize that concerns about inclusion are multi-dimensional (Sharma and Desai, 2002). The CIES measured the concerns of principals and classroom teachers about inclusive schools. Sharma and Desai (2002) developed the 21-item scale, with a four-point Likert-type classification ranging from extremely concerned (4) to not concerned at all (1). The factor analysis highlighted four factors, indicating a multi-dimensional construct, explaining the concerns about inclusive education. First, were the concerns about resources, which include those in respect of resources and financial support. Second, were the concerns about acceptance, which include the acceptance of students with SEN. Third, were the concerns about academic standards. Lastly, the fourth factor was concerns about the teachers' workload in an inclusive environment. Sharma and Desai (2002) calculated Cronbach's $\alpha$ for each scale and for the total scale (0.91). Looking at the results, countries with positive attitudes show less concerns. Predictors of concerns were age, experience, self-efficacy, 
contact with people with disabilities and the inclusive practice in a country. Sharma, Forlin, and Loreman (2007) re-analysed the CIES scale by using an exploratory principal component analysis, followed by a Varimax rotation, to conclude that the factor composition was analogous to the original scale (Sharma, Forlin, and Loreman, 2007). The items of the first and second factors are compatible with the 2002 study, but the third and fourth factors were changed (Sharma and Desai, 2002; Sharma, Forlin, and Loreman, 2007). In this re-analysis, the Cronbach's $\alpha$ of the first, second and fourth factors increased, with it decreasing for the third factor (Sharma, Forlin, and Loreman, 2007). We provide more details about the factor structure in the Result section.

\section{TEIP scale}

The TEIP (Sharma, Loreman, and Forlin, 2012) scale measures teachers' perceived self-efficacy in implementing inclusive practices. They stressed that the three-factorsscale was to have practical relevance for teacher educators. The scale determined the perceived efficacy of participants in teacher education programmes. It contains 18 items with a six-point Likert scale, ranging from strongly disagree (1) to strongly agree (6). Three efficacy subscales were identified: (1) using inclusive instruction, (2) in collaboration and (3) in managing behaviour. The Cronbach's $\alpha$ for the total scale ranged from 0.86 to 0.91 , depending on the country. Loreman, Sharma, and Forlin (2013) verified the three subscales with a principal components analysis. Park, Dimitrov, Das, et al. (2016) identified a reliability of the scale with a strong coefficient alpha 0.977. A bi-factor model highlighted '...that the TEIP scale data are essentially unidimensional, with one general factor and three specific latent factors (EII, EC and EMB) that represent unique aspects of teacher self-efficacy on teaching in inclusive classrooms' (Park, Dimitrov, Das, et al., 2016, p. 6). Sharma and Jacobs (2016, p. 18) pointed out that 'one factor congeneric measurement modelling of the TIEP scale confirmed the anticipated three-factor structure in both the Australian and Indian samples'. In another study, Sharma, Shaukat and Furlonger (2015) found Cronbach's $\alpha$ of over 0.70 , except for the third factor which was only 0.61 (Sharma, Shaukat, and Furlonger, 2015). The same study showed a significant negative correlation between attitudes and self-efficacy $(r=-0.165)$ (Sharma, Shaukat, and Furlonger, 2015).

\section{Research questions}

Our first goal is to validate our German translations of the AIS, ITICS, CIES and the TEIP. To do so, we planned to examine the fits and structure of factor analyses of the four instruments in our study. If our German version is an acceptable translation, we should be able to produce an acceptable fit when using the same structure as established in earlier work (Park, Dimitrov, Das, et al., 2016; Sharma and Desai, 2002; Sharma and Jacobs, 2016; Sharma, Loreman, and Forlin, 2012). Thus, our first two research questions are:
(1) Do the AIS, ITICS, CIES and TEIP have acceptable fits in separate confirmatory factor analyses (CFAs)

(2) Does their structure, and their fit, in separate CFAs match the findings of previous work

Next, previous work (Ahsan, Sharma, and Deppeler, 2012; Forlin, Loreman, Sharma, et al., 2009; Sharma, Forlin, Loreman, et al., 2006; Sharma and Sokal, 2016; Sokal, Woloshyn, and Funk-Unrau, 2013) has established that teachers and student teachers with greater concerns measured on the CIES, have lower self-efficacy, attitudes and intentions to teach in inclusive classrooms, as measured by the TEIP, AIS and ITICS - thus, our third question:

(3) In a combined model of all the four instruments (see Figure 1), are lower concerns related to greater selfefficacy, attitudes and intentions to teach in an inclusive classroom

Lastly, previous work (Forlin, Loreman, Sharma, et al., 2009; Sokal, Woloshyn, and Funk-Unrau, 2013) has established a relationship between student teachers, after having attended courses on inclusive education, and those without any courses on inclusive education. Specifically, we expect student teachers, who study special education, to have higher self-efficacy, higher-rated attitudes and lower concerns towards teaching in an inclusive environment. Similarly, they should have stronger intentions to teach in an inclusive classroom. However, to make a comparison between these groups, we must first establish that our instruments demonstrate measurement invariance. Thus, our last two research questions are:

(4) Are the instruments invariant between special education student teachers and general student teachers, when compared in separate CFAs

(5) Do special education student teachers have lower concerns, attitudes that are more positive and higher selfefficacy about inclusive education, and do they show stronger intentions to teach in an inclusive classroom

\section{Methods}

\section{Participants}

Participants were 909 (of which 76\% were female), enrolled in either bachelor level or master's level teachertraining programmes at a large German university. Of these, $22(2.5 \%)$ did not answer $10 \%$ or more of the survey and were therefore removed from the analyses. Most of the removed subjects skipped one or more entire pages of the survey.

Subjects attended one of five teacher-training tracks. These tracks included elementary school (Grundschule; $n=294$ ), lower secondary school (Hauptschule, Realschule, Gesamtschule; $n=119)$, upper secondary school (Gymnasiale Oberstufe; $n=202$ ), vocational schools (Berufskolleg; $n=81$ ) and special schools 
Notes: Individual items are not shown. Please see Table 1 for a list of all items and which factor they belong to. Bel refers to beliefs. Feel refers to feelings. Con refers to consulting. Curr refers to curriculum change. Res refers to resources. Com refers to competence. AS refers to academic standards. WL refers to workload. Inst refers to instruction. Coll refers to collaboration. Man refers to managing behaviour.

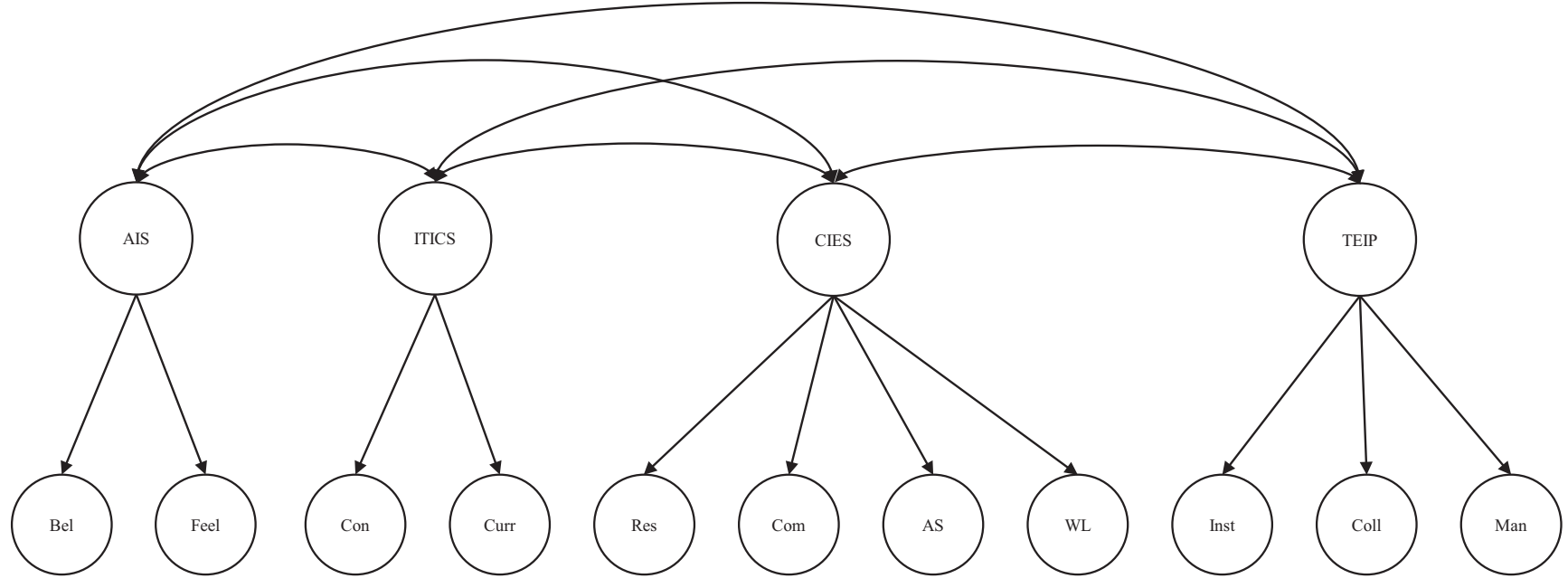

(Förderschule; $n=191$ ). As only students training for special education are required to take classes on inclusive education, we divided our participants into two groups: students training to teach in special schools $(n=191)$ and all other students $(n=696)$. We conducted a series of Mann-Whitney $U$-tests which confirmed that students preparing for teaching in special schools attended more classes relating to inclusive education.Although students on the other tracks attended a similar number of courses on inclusive education; all $P$-values between elementary, lower secondary, upper secondary and vocational tracks $>0.05$; all $P$-values between special education and all other tracks $<0.001$.

\section{Instruments}

New German translations of the AIS, ITICS, CIES and TEIP were created. The items are summarized briefly in English on Table 1. Native speakers of both English and German collaborated on the translation to ensure the literal and cultural meaning of each item was preserved.

\section{Analyses}

Group comparisons. Between groups, $t$-tests were calculated to compare average scores (excluding items dropped from factor analyses) between students preparing for special-education schools compared to all other students.

Factor analyses. Separate CFAs were conducted in Mplus 7.4 (Muthén and Muthén, 1998-2010) using robust maximum likelihood estimation for each instrument. We tested Sharma and Jacobs (2016) recommended two-factor structure of the AIS, and their two factor structure of the ITICS. We also tested Sharma and Desai's (2002) fourfactor structure of the CIES and three-factor structure of TEIP proposed by Park, Dimitrov, Das, et al. (2016). A fit was considered acceptable with RMSEA $<0.08$, CFI $>0.90$, SRMR $<0.08$ and gamma-hat $>0.90$; the fit was considered good when it had RMSEA $<0.05$, CFI $>0.95$, SRMR $<0.05$, and gamma-hat $>0.95$ ( $\mathrm{Hu}$ and Bentler, 1998).

The structure for each CFA is further detailed in Table 1. The AIS into two latent factors, beliefs and feelings, with items 5 and 6 being discarded. These two items had a poor fit in previous research, and their removal was recommended by Sharma and Jacobs (2016) for future development of the AIS. Similarly, the ITICS was divided into two latent variables, i.e., 'intention to make curriculum changes' and 'intentions to consult with other' (Sharma and Jacobs, 2016). The CIES was divided into four factors: resources, acceptance, reduced academic standards and workload (Sharma and Desai, 2002). Lastly, we tested the three-factor structure (instruction, collaboration and managing behaviour) of the TEIP proposed by Park, Dimitrov, Das, et al. (2016), with items 6, 14 and 17 being removed.

Finally, as seen in Figure 1, a combined model was developed which incorporated the modified structures of each of the instruments into a single model. Each instrument was represented as a latent factor, with its subscales as lower order latent variables. Each of the instruments was allowed to co-vary with each other, allowing us to use the co-variances to examine the hypothesized relationships between each of the instruments. 
Table 1: Item descriptions \& model structure

\begin{tabular}{|c|c|c|}
\hline Latent factor & Item & Abbreviated English description \\
\hline \multicolumn{3}{|l|}{ AIS } \\
\hline \multirow[t]{4}{*}{ Beliefs } & 1 & $\begin{array}{l}\text { All Students should be taught in regular } \\
\text { classrooms }\end{array}$ \\
\hline & 2 & $\begin{array}{l}\text { Inclusion is beneficial to all students } \\
\text { socially }\end{array}$ \\
\hline & 3 & $\begin{array}{l}\text { Inclusion is beneficial to all students } \\
\text { academically }\end{array}$ \\
\hline & 4 & $\begin{array}{l}\text { Students can learn inclusively with adapted } \\
\text { curriculum }\end{array}$ \\
\hline \multirow[t]{4}{*}{ Feelings } & 7 & $\begin{array}{l}\text { Pleased to teach students with lower } \\
\text { academic ability }\end{array}$ \\
\hline & 8 & $\begin{array}{l}\text { Excited to teach to students with wide } \\
\text { ranging abilities }\end{array}$ \\
\hline & 9 & Inclusion will improve my teaching \\
\hline & 10 & $\begin{array}{l}\text { Including those who need assistance for } \\
\text { daily activities }\end{array}$ \\
\hline \multicolumn{3}{|l|}{ ITICS } \\
\hline \multirow{3}{*}{$\begin{array}{l}\text { Curriculum } \\
\text { change }\end{array}$} & 11 & Change curriculum to meet learning needs \\
\hline & 16 & $\begin{array}{l}\text { Socially Include students with severe } \\
\text { disabilities }\end{array}$ \\
\hline & 17 & Change assessment tasks \\
\hline \multirow[t]{3}{*}{ Consulting } & 12 & Consult with parents \\
\hline & 13 & Consult with colleagues \\
\hline & 14 & Undertake professional development \\
\hline Both* & 15 & $\begin{array}{l}\text { Consult with student to find ways to improve } \\
\text { instruction }\end{array}$ \\
\hline \multicolumn{3}{|l|}{ CIES } \\
\hline \multirow[t]{3}{*}{ Competence $^{\dagger}$} & 1 & Not enough time \\
\hline & 2 & Difficult to maintain discipline \\
\hline & 3 & Lack of knowledge and skills \\
\hline \multirow[t]{6}{*}{ Resources } & 7 & Not enough funds \\
\hline & 8 & Inadequate para-professional staff \\
\hline & 12 & Inappropriate Infrastructure \\
\hline & 13 & Inadequate special-ed staff \\
\hline & 14 & Inadequate instructional materials \\
\hline & 20 & Inadequate administrative support \\
\hline \multirow{6}{*}{$\begin{array}{l}\text { Academic } \\
\text { standards }\end{array}$} & 15 & Decline of school academic standards \\
\hline & 16 & Decline of educators' performance \\
\hline & 17 & $\begin{array}{l}\text { Decline of academic achievement of children } \\
\text { w/o SEN }\end{array}$ \\
\hline & 18 & Difficult to divide attention \\
\hline & 19 & $\begin{array}{l}\text { Integrating students requiring assistance in } \\
\text { self-help skill }\end{array}$ \\
\hline & 21 & High anxiety and stress in teachers \\
\hline Workload & 4 & Additional paperwork \\
\hline
\end{tabular}

Table 1: (Continued)
Table 1: (Continued)

\begin{tabular}{|c|c|c|}
\hline Latent factor & Item & Abbreviated English description \\
\hline & 9 & Lack of incentives \\
\hline & 10 & Increased workloads \\
\hline & 11 & Increased stress in other staff \\
\hline \multicolumn{3}{|l|}{ TEIP } \\
\hline \multirow[t]{5}{*}{ Instruction } & 1 & Variety of assignment strategies \\
\hline & 2 & Alternate examples \\
\hline & 3 & $\begin{array}{l}\text { Design learning tasks accommodating } \\
\text { students with SEN }\end{array}$ \\
\hline & 4 & Accurately gauge comprehension \\
\hline & 5 & Can challenge highly capable students \\
\hline Managing & 7 & Confident to prevent disruptive behaviour \\
\hline \multirow[t]{5}{*}{ behaviour } & 8 & Can control disruptive behaviour \\
\hline & 9 & Can calm loud or disruptive students \\
\hline & 10 & Can get students to follow classroom rules \\
\hline & 11 & $\begin{array}{l}\text { Confident in dealing with physically } \\
\text { aggressive students }\end{array}$ \\
\hline & 12 & $\begin{array}{l}\text { Can make expectations about student } \\
\text { behaviour clear }\end{array}$ \\
\hline \multirow[t]{5}{*}{ Collaboration } & 13 & $\begin{array}{l}\text { Can assist families to help their children do } \\
\text { well }\end{array}$ \\
\hline & 15 & $\begin{array}{l}\text { Can to work with other staff to teach } \\
\text { students with SEN }\end{array}$ \\
\hline & 16 & $\begin{array}{l}\text { Can encourage parent involvement of } \\
\text { children with SEN }\end{array}$ \\
\hline & 17 & $\begin{array}{l}\text { Involve staff when designing learning plans } \\
\text { for students with SEN }\end{array}$ \\
\hline & 18 & $\begin{array}{l}\text { Confident to inform others about laws and } \\
\text { rights for learners with SEN }\end{array}$ \\
\hline
\end{tabular}

Notes: *Item 15 of the ITICS was allowed to load onto both consulting and curriculum change latent factors. ${ }^{\dagger}$ Competence scale was renamed from acceptance after items 4 and 5 were removed. Some items were removed from the original scales. Please see methods and results for details. Italicized items are items whose intercepts were freed when testing for partial invariance.

Invariance analyses. In the above group comparisons analysis, we compare average scores on the instruments; however, in order to this comparison to be meaningful, invariance must be established for each model across the comparison groups. We established invariance between pre-service teachers studying to teach in special schools and general teachers by testing the fits of configural against metric models (weak invariance), and metric against scalar models (strong invariance) (Dimitrov, 2010). When invariance was not achieved at the scalar level, we tested for partial invariance by freeing intercepts (in the order of greatest contribution to $\mathrm{X}^{2}$ ) in the scalar model until the modified scalar model was below both critical thresholds of $0.01 \Delta \mathrm{CFI}$ and $0.02 \Delta$ gamma-hat (Cheung and Rensvold, 2002). 


\section{Results}

Mean score comparisons

Table 2 summarizes the comparisons of mean scores between students studying to become special-education teachers, compared to all other general pre-service teacher groups. Except for resources from the CIES and beliefs from the AIS, significant effects were found for all composite scales and all subscales, $P<0.001$, where significant. We also report the effect size measured by Cohen's D (Cohen, 1988). For Cohen's D, effect sizes of 0.2 can be interpreted as small, 0.5 as medium and 0.8 as large. Using these rough guidelines, we found large effects for the composite scores of the ITICS, CIES and TEIP, and a medium effect for the composite score of the AIS. Similarly, we found large effects for the subscales of curriculum change on the ITICS, competence and academic impact on the CIES, and collaboration on the TEIP. Medium effects were found for the subscales of consulting on the ITICS and workload on the CIES. Lastly, small effects were found for

Table 2: Comparison between special education teaching students and students preparing to teach in other school types

\begin{tabular}{|lccc|}
\hline & $\begin{array}{c}\text { Special } \\
\text { education }\end{array}$ & $\begin{array}{c}\text { Other school } \\
\text { types }\end{array}$ & $\begin{array}{c}\text { Effect } \\
\text { size } \\
\text { Cohen's } \\
\text { M (SD) }\end{array}$ \\
\hline AIS & M (SD) & D \\
Beliefs & $4.3(1.4)$ & $4.4(1.3)$ & $n . s$. \\
Feelings & $5.5(1.3)$ & $4.7(1.2)$ & 0.64 \\
Composite & $4.9(1.1)$ & $4.5(1.1)$ & 0.37 \\
ITICS & & & \\
Consulting & $6.1(0.7)$ & $5.5(0.9)$ & 0.74 \\
Curriculum & $5.7(0.8)$ & $4.7(1.1)$ & 1.04 \\
Composite & $6.0(0.7)$ & $5.2(0.5)$ & 1.32 \\
CIES & & & \\
Resources & $2.9(0.6)$ & $3.0(0.6)$ & $n .5$. \\
Competence* & $2.1(0.6)$ & $2.8(0.6)$ & 1.17 \\
Academic & $1.8(0.5)$ & $2.3(0.6)$ & 0.91 \\
standards & & & \\
Workload & $2.3(0.5)$ & $2.6(0.5)$ & 0.60 \\
Composite & $2.2(0.4)$ & $2.6(0.5)$ & 0.88 \\
TEIP & & & \\
Instruction & $4.8(0.6)$ & $4.5(0.7)$ & 0.46 \\
Collaboration & $5.0(0.6)$ & $4.3(0.8)$ & 0.99 \\
Managing & $4.5(0.7)$ & $4.3(0.8)$ & 0.27 \\
Composite & $4.8(0.5)$ & $4.3(0.6)$ & 0.90 \\
\hline
\end{tabular}

Notes: *Competence was renamed from acceptance. Based on invariance estimations, we urge caution when interpreting any comparisons for this subscale. Please see our section on invariance results for details. Scores were calculated by averaging all scores together for a given scale. The composite scores for each instrument were calculated by averaging each item on the instrument and not by averaging the subscales together. Items excluded from our factor analyses were excluded from these calculations. n.s. denotes no significant effect, $P>0.05$. All other effects were significant at $P<0.0001$. the subscales of instruction and managing behaviour on the TEIP. However, we urge caution in the interpretation of any effects for the competence subscale of the CIES (see invariance tests below).

To sum up, we see predicted significant differences between our participant groups. Students studying special education displayed the most positive feelings, greater self-efficacy, more positive intentions to teach inclusively, and fewer concerns regarding inclusive education and learners with SEN. However, both student groups shared similar attitudes towards inclusive education and similar concerns about the workload involved.

\section{Model fits and modifications}

Model fits for the individual instruments are presented in Table 3. Overall fits ranged from acceptable to good, although some minor modifications were required for the ITICS and CIES scales. We have summarized the results and any modifications, which were required below:

AIS. The AIS produced fits ranging from good to acceptable on all metrics and required no modification.

ITICS. The ITICS had acceptable values for CFI and gamma-hat, but its RMSEA was too high. We allowed item 15 to load onto both factors rather than only intention to consult. This item involves making changes to adapt to a specific child, rather than specifically consulting with other teachers or parents and it is therefore likely to share some variance with both latent variables, rather than just one. This modification produced an acceptable model.

CIES. The CIES had a CFI well below the acceptable level and several modifications were required to obtain an acceptable fit. Items 4 and 5 had very low factor loadings, so we removed them from the acceptance factor. The remaining items were not related to acceptance, so we renamed this factor competence. We

Table 3: Model fits

\begin{tabular}{|lcccc|}
\hline & CFI & Gamma- & & \\
& hat & RMSEA (90\% CI) & SRMR \\
\hline AIS & 0.980 & 0.990 & $0.052(0.039-0.067)$ & 0.027 \\
ITICS & 0.931 & 0.974 & $0.097(0.082-0.114)$ & 0.042 \\
ITICS, & 0.974 & 0.989 & $0.063(0.046-0.080)$ & 0.026 \\
$\quad$ modified & & & & \\
CIES & 0.817 & 0.914 & $0.077(0.073-0.081)$ & 0.066 \\
CIES, modified & 0.910 & 0.959 & $0.059(0.054-0.064)$ & 0.050 \\
TEIP & 0.913 & 0.956 & $0.066(0.061-0.072)$ & 0.069 \\
Combined & 0.880 & 0.935 & $0.044(0.042-0.046)$ & 0.056 \\
\hline
\end{tabular}

Note: Minor model modifications that were made are described in the methods section. 
also moved item 17 into the reduced academic standards factor, because it relates more to academic standards and does not involve the teacher's workload. We then allowed items 15 and 16 to co-vary, and items 3 and 19 to co-vary, too. Items 15 and 16 both involved similar aspects of academic standards, and item 19 may refer to specific skills required in an inclusive environment, while item 3 may relate to skills in general. These modifications produced a model with an acceptable fit.

This new competence factor should not be considered the same as the old acceptance factor. Indeed, all items relating to concerns about acceptance were removed from this factor. The new factor only measures concerns related to teacher competence. However, the majority of the items on the factor are retained, so the overall effect of removing the two items on the CIES is minor.

TEIP. The TEIP model produced fits ranging from acceptable to good and required no modifications.

Combined model. The combined model was developed from the modified version of the four instruments, with an instrument-level higher order factor for each instrument (e.g., the AIS was a top-level factor, with two sub-factors, feelings and beliefs, which were composed of the relevant items). The combined model includes a fit for the CFI, which is just below our threshold; however, the other fit indices indicate an acceptable or a good fit. We therefore concluded that the fit was acceptable. Furthermore, any further fit modifications would cause the model to deviate from the model structure we had used in other instrument models. We therefore decided it would be inappropriate to make further modifications of the combined model's structure, as we would otherwise have a structure that may imply different latent variables than the separate models of the four instruments.

\section{Invariance tests}

As summarized in Table 4, all the models met the requirements for weak (metric) invariance. However, only the ITICS model met the requirements for strong (scalar) invariance. The other scales met requirements for partial invariance after the freeing of a small number of intercepts. Two (13\% of loadings and intercepts) were freed for the AIS, five (13\% of loadings and intercepts) were freed for the CIES, and two (6\% of loadings and intercepts) were freed for the TEIP. These intercepts are italicized in Table 1. These values are well below our threshold of $20 \%$ freed loadings and intercepts for partial invariance.

It is important to point out that a potential solution for the CIES involved freeing only four intercepts; however, this would have involved freeing all the intercepts for the competence subscale, which would cause the model to be unidentified. As this is also the scale, which required the most modification to achieve an acceptable fit, we argue
Table 4: Invariance tests

\begin{tabular}{|lcccc|}
\hline & CFI & Gamma-hat & $\Delta$ CFI & $\Delta$ Gamma-hat \\
\hline AIS & & & & \\
Configural & 0.980 & 0.979 & & \\
Metric & 0.976 & 0.975 & 0.004 & 0.004 \\
Scalar & 0.955 & 0.953 & $0.021^{*}$ & $0.022^{*}$ \\
Scalar, partial & 0.969 & 0.969 & 0.007 & 0.006 \\
ITICS & & & & \\
Configural & 0.962 & 0.972 & & \\
Metric & 0.964 & 0.973 & -0.002 & -0.001 \\
Scalar & 0.960 & 0.971 & 0.004 & 0.002 \\
CIES & & & & \\
Configural & 0.908 & 0.922 & & 0.001 \\
Metric & 0.907 & 0.921 & 0.001 & $0.037^{*}$ \\
Scalar & 0.854 & 0.884 & $0.053^{*}$ & 0.005 \\
Scalar, partial & 0.900 & 0.916 & 0.007 & 0.007 \\
TEIP & & & & 0.003 \\
Configural & 0.910 & 0.910 & & 0.002 \\
Metric & 0.907 & 0.908 & 0.009 & \\
Scalar & 0.890 & 0.892 & $0.017^{*}$ & 0.016 \\
Scalar, partial & 0.898 & 0.901 & 0.009 & 0.007 \\
\hline
\end{tabular}

Notes: *Indicates a significantly worse of fit (i.e., exceeding critical thresholds of $\Delta$ CFI $=0.010$ and $\Delta$ gamma-hat $=0.020 . \Delta$ CFI and $\Delta$ gamma-hat represent the change in these fit metrics between the current and next less restrained model (i.e., configural CFI - metric CFI; metric CFI - scalar CFI; or metric CFI - partial scalar CFI, or the same differences using gamma-hat).

that strong conclusions, as regards the differences between special-education student teachers and other student teachers, should not be made with this specific subscale.

To sum up, we found sufficient strong and partial invariance for these instruments, with the exception the subscale of competence for the CIES.

\section{Co-variation}

Table 5 shows the standardized co-variation values of the all four instruments in the combined model. All the covariations were significant, $P<0.001$. As these are standardized values, these can be interpreted in a similar way to correlations between the latent values. The TEIP, AIS and ITICS had significant positive co-variation with each other, and the CIES had a significantly negative covariation with the other three scales (TEIP, AIS and ITICS).

\section{Discussion}

The purposes of this study were to examine whether existing scales on attitudes to inclusion, self-efficacy and concerns were appropriate for a German pre-service teacher group. We investigated how the four scales related to each other and if there were differences between general and special education teachers. The AIS, ITICS, 
Table 5: Covariation between instruments in the combined model

\begin{tabular}{|lrrrr|}
\hline & AIS & ITICS & CIES & TEIP \\
\hline AIS & 1.000 & & & \\
ITICS & 0.711 & 1.000 & & \\
CIES & -0.637 & -0.610 & 1.000 & \\
TEIP & 0.635 & 0.736 & -0.686 & 1.000 \\
\hline
\end{tabular}

Note: All values are standardized. All values were significant, $P<0.001$.

TEIP and CIES scales have been verified in a variety of international studies (Sharma and Desai, 2002; Sharma, Forlin, and Loreman, 2007; Sharma and Jacobs, 2016; Sharma, Loreman, and Forlin, 2012), but never validated in this combination of all the scales together. First, we looked into the fits and structure of the factor analyses of the four instruments in our study. As regards our research questions, the investigations show that the structure of the existing and testing scales (AIS, ITICS, TEIP, CIES) also fit in the translated version. The undertaken CFAs confirmed the factors of AIS, ITICS and TEIP, however, two items were removed from the CIES. We assume that the construct behind the scales and items is appropriately phrased in the German translation, with the possible exceptions of the items removed from the CIES. More research on the factor structure of the CIES in different language versions is required to clarify this particular issue. After calculating each model separately a combined model was calculated in which second order factors to covariedy with each other. Based on the earlier work, we wished to examine if lower concerns related to higher self-efficacy, attitudes and intentions to teach in an inclusive classroom, our calculations match previous studies (Sharma and Sokal, 2015, 2016). In the combined model, we compared not just the scores of individual subjects, but the relationships between the modelled latent variables across the four instruments. Further research could focus more on combining these instruments.

In regards to our research questions, we can conclude that the results are invariant between special-education and general education pre-service teachers. This is the first comparison, of which we are aware, that measures invariance on these instruments between special-education student teachers and other student teachers. This means that meaningful instrument comparisons can be made between these groups on these individual instruments. In such comparisons, we found that special-education pre-service teachers display more positive attitudes, greater self-efficacy, stronger intentions to teach inclusively and fewer concerns regarding inclusive education and learners with SEN. Notably, results highlight that lower concerns relate to higher values on the AIS, ITICS and TEIP scales. This corresponds to previous findings (Sharma and Jacobs, 2016) highlighting the relationship between concerns, attitudes, self-efficacy and the intention to teach inclusively.
However, it is important to note that, while we were able to affirm partial invariance for the CIES, we were not able to do so for the competence subscale. We recommend against using this subscale individually for comparisons, and instead recommend using the full CIES for this purpose. Another key limitation is that the results are based only on the German pre-service teachers. We lack a direct comparison with the same four scales with participants from other countries. Future research might confirm and validate our results. To summarize, the tested four instruments operate similarly to other countries in a German group. Comparable to other studies, lower concerns relate to better attitudes, stronger intentions to teach inclusively and greater self-efficacy. Future work should provide international comparisons and further examine the competence items of the CIES. Our combined model can also be taken as first step towards combining these instruments into a simplified instrument to allow for a more efficient measurement of teachers' and student teachers' attitudes, concerns, competency and self-efficacy.

In conclusion, our German translations of the AIS, ITICS, CIES and TEIP function well and produce similar results to other language versions of these instruments. Our combined model was able to describe the way concerns about inclusion can reduce attitudes, efficacy and the intention to teach inclusively. Lastly, while we found sufficient invariance between special- education student teachers and other student teachers, further tests of invariance between the different groups is necessary to validate these instruments as they continue to be developed.

Address for correspondence

Susanne Miesera,

TUM School of Education,

Arcisstraße 21,

80333 München,

Germany.

Email: susanne.miesera@tum.de.

\section{References}

Ahmmed, M., Sharma, U. \& Deppeler, J. (2012)

'Variables affecting teachers' attitudes towards inclusive education in Bangladesh.' Journal of Research in Special Educational Needs, 12 (3), pp. 132-40.

Ahsan, M. T., Deppeler, J. M. \& Sharma, U. (2013)

'Predicting pre-service teachers' preparedness for inclusive education: Bangladeshi pre-service teachers' attitudes and perceived teaching-efficacy for inclusive education.' Cambridge Journal of Education, 43 (4), pp. 517-35.

Ahsan, M. T., Sharma, U. \& Deppeler, J. (2012) 'Exploring pre-service teachers' perceived teachingefficacy, attitudes and concerns about inclusive 
education in Bangladesh.' International Journal of Whole Schooling, 8 (2), pp. 1-20.

Antonak, R. F. \& Larrivee, B. (1995) 'Psychometric analysis and revision of the opinions relative to mainstreaming scale.' Exceptional Children, 62 (2), pp. 139-49.

Avramidis, E. \& Norwich, B. (2002) 'Teachers' attitudes towards integration/inclusion: a review of the literature.' European Journal of Special Needs Education, 17 (2), pp. 129-47.

Bandura, A. (1997) Self-Efficacy: The Exercise of Control. New York, NY: W.H. Freeman.

Beacham, N. \& Rouse, M. (2012) 'Student teachers' attitudes and beliefs about inclusion and inclusive practice.' Journal of Research in Special Educational Needs, 12 (1), pp. 3-11.

de Boer, A., Pijl, S. J. \& Minnaert, A. (2011) 'Regular primary schoolteachers' attitudes towards inclusive education: a review of the literature.' International Journal of Inclusive Education, 15 (3), pp. 331-53.

Boyle, C., Topping, K. \& Jindal-Snape, D. (2013) 'Teachers' attitudes towards inclusion in high schools.' Teachers and Teaching, 19 (5), pp. 527-42.

Brownlee, J. \& Carrington, S. (2000) 'Opportunities for authentic experience and reflection: a teaching programme designed to change attitudes towards disability for pre-service teachers.' Support for Learning, 15 (3), pp. 99-105.

Cheung, G. W. \& Rensvold, R. B. (2002) 'Evaluating goodness-of-fit indexes for testing measurement invariance.' Structural Equation Modeling, 9 (2), pp. 233-55.

Cohen, J. (1988) Statistical Power Analysis for the Behavioral Sciences (2nd edn). Hillsdale, NJ: Lawrence Erlbaum Associates.

Copfer, S. \& Specht, J. (2014) 'Measuring effective teacher preparation for inclusion.' In C. Forlin (ed), International Perspectives on Inclusive Education. Measuring Inclusive Education, pp. 93-105. Bingley: Emerald Group Publishing Limited.

Dimitrov, D. M. (2010) 'Testing for factorial invariance in the context of construct validation.' Measurement and Evaluation in Counseling and Development, 43 (2), pp. 121-49.

Florian, L. \& Black-Hawkins, K. (2011) 'Exploring inclusive pedagogy.' British Educational Research Journal, 37 (5), pp. 813-28.

Florian, L., Young, K. \& Rouse, M. (2010) 'Preparing teachers for inclusive and diverse educational environments: studying curricular reform in an initial teacher education course.' International Journal of Inclusive Education, 14 (7), pp. 709-22.

Forlin, C. (2010) 'Teacher education reform for enhancing teachers' preparedness for inclusion.' International Journal of Inclusive Education, 14 (7), pp. 649-53.

Forlin, C. \& Chambers, D. (2011) 'Teacher preparation for inclusive education: increasing knowledge but raising concerns.' Asia-Pacific Journal of Teacher Education, 39 (1), pp. 17-32.

Forlin, C., Loreman, T., Sharma, U. \& Earle, C. (2009)

'Demographic differences in changing pre-service teachers' attitudes, sentiments and concerns about inclusive education.' International Journal of Inclusive Education, 13 (2), pp. 195-209.

Forlin, C., Sharma, U. \& Loreman, T. (2014) 'Predictors of improved teaching efficacy following basic training for inclusion in Hong Kong.' International Journal of Inclusive Education, 18 (7), pp. 718-30.

Golmic, B. \& Hansen, M. (2012) 'Attitudes, sentiments, and concerns of pre-service teachers after their included experience.' International Journal of Special Education, 27 (1), pp. 27-36.

Hernandez, D. A., Hueck, S. \& Charley, C. (2016) 'General education and special education teachers' attitudes towards inclusion.' Journal of the American Academy of Special Education Professionals, Fall, pp. 79-93.

Hu, L.-T. \& Bentler, P. M. (1998) 'Fit indices in covariance structure modeling: sensitivity to underparameterized model misspecification.' Psychological Methods, 3 (4), pp. 424-53.

Jordan, A., Glenn, C. \& McGhie-Richmond, D. (2010) 'The Supporting Effective Teaching (SET) project: the relationship of inclusive teaching practices to teachers' beliefs about disability and ability, and about their roles as teachers.' Teaching and Teacher Education, 26 (2), pp. 259-66.

Kim, J. (2011) 'Influence of teacher preparation programmes on preservice teachers' attitudes toward inclusion.' International Journal of Inclusive Education, 15 (3), pp. 355-77.

Kopp, B. (2009) 'Inklusive Überzeugung und Selbstwirksamkeit im Umgang mit Heterogenität: Wie denken Studierende des Lehramts für Grundschulen?' Empirische Sonderpädagogik, 1, pp. $5-25$.

Loreman, T., Earle, C., Sharma, U. \& Forlin, C. (2007) 'The development of an instrument for measuring preservice teachers' sentiments, attitudes, and concerns about inclusive education.' International Journal of Special Education, 22 (1), pp. 150-9.

Loreman, T., Forlin, C. \& Sharma, U. (2014) 'Measuring indicators of inclusive education: a systemativ review of the literature.' In C. Forlin (ed), International Perspectives on Inclusive Education. Measuring Inclusive Education, pp. 165-88. Bingley: Emerald Group Publishing Limited.

Loreman, T., Sharma, U. \& Forlin, C. (2013) 'Do preservice teachers feel ready to teach in inclusive classrooms? A four country study of teaching selfefficacy.' Australian Journal of Teacher Education, 38 (1), pp. 27-44.

Miesera, S. \& Gebhardt, M. (2018) 'Inclusive vocational schools in Canada and Germany. A comparison of vocational pre-service teachers' ${ }^{\prime}$ attitudes, self-efficacy, 
and experiences towards inclusive education.'

European Journal of Special Needs Education, 8 (2), pp. $1-16$.

Muthén, L. K. \& Muthén, B. O. (1998-2010) Mplus User's Guide (6 Ausgabe). Los Angeles, CA: Muthén \& Muthén.

O’Toole, C. \& Burke, N. (2013) 'Ready, willing and able? Attitudes and concerns in relation to inclusion amongst a cohort of Irish pre-service teachers.'

European Journal of Special Needs Education, 28 (3), pp. 239-53.

Park, M.-H., Dimitrov, D. M., Das, A. \& Gichuru, M. (2016) 'The teacher efficacy for inclusive practices (TEIP) scale: dimensionality and factor structure.' Journal of Research in Special Educational Needs, 16 (1), pp. 2-12.

Romi, S. \& Leyser, Y. (2006) 'Exploring inclusion preservice training needs: a study of variables associated with attitudes and self-efficacy beliefs.' European Journal of Special Needs Education, 21 (1), pp. 85-105.

Saloviita, T. \& Schaffus, T. (2016) 'Teacher attitudes towards inclusive education in Finland and Brandenburg, Germany and the issue of extra work.' European Journal of Special Needs Education, 31 (4), pp. $1-14$.

Savolainen, H., Engelbrecht, P., Nel, M. \& Malinen, O.P. (2012) 'Understanding teachers' attitudes and selfefficacy in inclusive education: implications for preservice and in-service teacher education.' European Journal of Special Needs Education, 27 (1), pp. 5168.

Schwab, S., Gebhardt, M., Ederer-Fick, E. M. \& Gasteiger Klicpera, B. (2012) 'An examination of public opinion in Austria towards inclusion. Development of the 'Attitudes Towards Inclusion Scale' - ATIS.' European Journal of Special Needs Education, 27 (3), pp. 355-71.

Sharma, U. \& Desai, I. (2002) 'Measuring concerns about integrated education in India.' Asia and Pacific Journal on Disability, 5 (1), pp. 2-14.

Sharma, U., Forlin, C. \& Loreman, T. (2007) 'What concerns pre-service teachers about inclusive education: an international viewpoint?' KEDI Journal of Educational Policy, 4 (2), pp. 95-114.

Sharma, U., Forlin, C. \& Loreman, T. (2008) 'Impact of training on pre-service teachers' attitudes and concerns about inclusive education and sentiments about persons with disabilities.' Disability \& Society, 23 (7), pp. 773-85.

Sharma, U., Forlin, C., Loreman, T. \& Earle, C. (2006)

'Pre-service teachers' attitudes, concerns and sentiments about inclusive education: an international comparison of novice pre-service teachers.'

International Journal of Special Education, 21 (2), pp. 80-93.

Sharma, U. \& Jacobs, D. K. (2016) 'Predicting in-service educators' intentions to teach in inclusive classrooms in India and Australia.' Teaching and Teacher

Education, 55, pp. 13-23.

Sharma, U., Loreman, T. \& Forlin, C. (2012) 'Measuring teacher efficacy to implement inclusive practices.' Journal of Research in Special Educational Needs, 12 (1), pp. 12-21.

Sharma, U., Moore, D. \& Sonawane, S. (2009) 'Attitudes and concerns of pre-service teachers regarding inclusion of students with disabilities into regular schools in Pune, India.' Asia-Pacific Journal of Teacher Education, 37 (3), pp. 319-31.

Sharma, U. \& Nuttal, A. (2016) 'The impact of training on pre-service teacher attitudes, concerns, and efficacy towards inclusion.' Asia-Pacific Journal of Teacher Education, 44 (2), pp. 142-55.

Sharma, U., Shaukat, S. \& Furlonger, B. (2015) 'Attitudes and self-efficacy of pre-service teachers towards inclusion in Pakistan.' Journal of Research in Special Educational Needs, 15 (2), pp. 97-105.

Sharma, U. \& Sokal, L. (2015) 'The impact of a teacher education course on pre-service teachers' beliefs about inclusion: an international comparison.' Journal of Research in Special Educational Needs, 15 (4), pp. 276-84.

Sharma, U. \& Sokal, L. (2016) 'Can teachers' selfreported efficacy, concerns, and attitudes toward inclusion scores predict their actual inclusive classroom practices?' Australasian Journal of Special Education, 40 (1), pp. 21-38.

Shaukat, S., Sharma, U. \& Furlonger, B. (2013) 'Pakistani and Australian pre-service teachers' attitudes and self-efficacy towards inclusive education.' Journal of Behavioural Sciences, 23 (2), pp. $1-16$.

Sokal, L. \& Katz, J. (2017) 'Effects of the three-block model of universal design for learning on teachers' behaviours, efficacy, and concerns about inclusive teaching.' Teacher Education and Practice, 30 (1), pp. 157-76.

Sokal, L., Woloshyn, D. \& Funk-Unrau, S. (2013) 'How important is practicum to pre-service teacher development for inclusive teaching? Effects on efficacy in classroom management.' Alberta Journal of Educational Research, 59 (2), pp. 285-98.

Specht, J. (2016) 'Professional learning for inclusion in Canada.' Journal of Research in Special Educational Needs, 16 (1), pp. 894.

Specht, J., McGhie-Richmond, D., Loreman, T., Mirenda, P., Bennett, S., Gallagher, T. \& Cloutier, S. (2016) 'Teaching in inclusive classrooms: efficacy and beliefs of Canadian preservice teachers.' International Journal of Inclusive Education, 20 (1), pp. 1-15.

Stoiber, K. C., Gettinger, M. \& Goetz, D. (1998) 'Exploring factors influencing parents' and early childhood practitioners' beliefs about inclusion.' Early Childhood Research Quarterly, 13 (1), pp. 107-24.

Subban, P. \& Mahlo, D. (2017) 'My attitude, my responsibility' Investigating the attitudes and 
intentions of pre-service teachers toward inclusive education between teacher preparation cohorts in Melbourne and Pretoria.' International Journal of Inclusive Education, 21 (4), pp. 441-61.

Swain, K. D., Nordness, P. D. \& Leader-Janssen, E. M. (2012) 'Changes in preservice teacher attitudes toward inclusion.' Preventing School Failure:
Alternative Education for Children and Youth, 56 (2), pp. 75-81.

United Nations. (2006) ' 15 . Convention on the rights of persons with disabilities.' <https://www.un.org/deve lopment/desa/disabilities/convention-on-the-rights-ofpersons-with-disabilities.html> (accessed 05 February 2018). 